\title{
Evaluating the use of electronic networking for continuing professional development
}

\author{
KATHRYN LEACH \\ Department of Library and Information Studies \\ University of Brighton
}

This article reports on the British Library funded research project 'The use of information networking for continuing professional development' in progress at the University of Brighton.

The project aims to survey and review the current extent of, and promote interest in, the delivery of programmes of continuing professional development (CPD) for information professionals by means of computer networks, network-based course materials and computer conferencing. It will assess the degree of professional demand for programmes of this nature and evaluate the opportunities for, and barriers to, future development in this area with a particular emphasis on the support of European collaboration.

The recent substantial growth in information networking is likely to be a major influence on the future work patterns of library and information professionals. The profession will have the opportunity to use a wide range of networked information sources and systems, to communicate with groups within the profession through electronic means, and to use new integrated information formats. All of these innovations offer potential for the development of new forms and types of information service and imply changes in the role of the information professional.

Within the broader context, there is also an increased emphasis placed on the dynamics of organizational change and development, as expressed, for example, in ideas of the networked organization; the importance of information in innovation management; and the role of communication systems in 'organizational learning'. An ability to participate in these movements may help provide the basis for information workers to move from an institutional to a functional mode of working - to move out of the library and into the organization.

Such information workers often operate in professional isolation. They may not have attained a Library and Information Studies undergraduate or postgraduate degree, and may have been recruited from other disciplines such as computer science and business administration. Furthermore,

"... the people who are appointed to these positions do not generally perceive themselves to be part of the library and information community"(1).

It is therefore important to address how best to deliver CPD to all information workers. The established and recognized information profession can disseminate its skills and knowledge whilst learning skills from the new recruits to the profession. Such a training programme would help to unite the profession further.

\section{The delivery of Continuing Professional Development}

A number of national and international initiatives are involved in developing teaching and learning material of the kind under discussion. The Teaching and Learning Technology Projects (TLTP) programme is one such activity. The aim of this programme is to make teaching and learning more productive and efficient by harnessing modern technology ${ }^{(2)}$. Many of the projects under the TLTP programme involve the development of material which can be delivered outside the classroom, 
thus making it suitable for CPD using networks and computers based at the place of work.

Of more relevance to the information profession has been the development under the European Commission's IMPACT programme of training courses aimed at information professionals to assist them to adapt to a world in which an increasing amount of information is held electronically. Some of these courses have been designed to be delivered with an element of distance learning in them. A start on the route being explored by this project.

The work being done under the EU DELTA programme is more to do with distance learning than the TLTP projects. The important point about all these programmes are that they are using network and computer technology to deliver teaching and learning packages and in so doing are extending the range of tools and also extending our understanding of the issues surrounding this mode of working. They are in effect preparing the groundwork for the delivery of teaching and learning materials by means of computer networks, network-based course materials and computer conferencing.

The Open University has run an interesting course which may point the way for the kind of CPD we have in mind. As Alexander ${ }^{(3)}$ says: 'In distance education courses the learning style is often primarily passive and interaction with other students as well as free exploration of learning resources is relatively little used'. The course XT001 - renewable energy technology - set out to explore learning approaches which were inherently conversational and collaborative, in which the students actively engaged with the learning materials through exploration and interaction. Given that one of the worries which is beginning to emerge from the survey is that of isolation of the learner, this approach may well be a pointer to an approach which can overcome such a sense of isolation. The OU course ran for the first time in October 1993 with 24 students from around the world. it involved the students in preparing material which was reviewed by their peers over the Internet using bulletin board software supplied to them.

In addition, the students were given material such as computer-based models and CD-ROMS which encouraged or required interactive experimentation.

The information professional needs to participate in CPD programmes to keep abreast of technological advances, government initiatives and budgetary restrictions in an increasingly competitive environment. These programmes could be delivered and supported by the use of electronic course material, computer conferencing and e-mail. This could range from complete electronic delivery of course modules to the use of e-mail to support print based material or to facilitate informal discussions after workshops or conferences.

Some information workers wishing to further their CPD have found that they are restricted from participation by a range of factors. A recent British Library report on continuing professional education by MacDougall, Lewins and Tseng ${ }^{(4)}$ found that many women members were unable to travel, thus preventing them from participating in seminars and discussions. Information professionals working independently within small units may find it difficult to obtain professional cover to free them to attend courses. There is a need to provide flexibility within course delivery. Electronic networked materials would allow students to access material without being restricted by location or set study periods, thus allowing a more equal access to CPD. 


\section{The research}

The project will evaluate two postal surveys. The first targeted institutions delivering LIS education within UK, Europe and North America, Australia, South Africa and Jamaica. This will analyze the institutions' current involvement in electronic delivery of CPD and their future plans. The results will highlight possibilities for future collaboration regarding the construction of CPD programmes within Europe and around the world.

The second survey will collect information regarding professional concerns and education delivered electronically from a representative sample of information workers within the UK. It will highlight the technical, social and economic barriers towards networked electronic CPD as well as the opportunties for progress in this area.

The first survey produced a high response rate from around the world. The quantitative aspects of the questionnaire are in the process of being analyzed. The more qualitative aspects have already shown a number of interesting developments which could be of value to the wider community. The most positive aspect of the survey is that there appears to be a willingness amongst the provided community to collaborate and share ideas and material. This must be of benefit to the information profession in attempting to meet their requirements for CPD.

\section{Preliminary results}

Preliminary results from the survey of institutions delivering LIS education have shown that the respondents from the UK and Europe have yet to deliver CPD programmes electronically. However, many include aspects of electronic networking within their undergraduate and postgraduate courses and are interested in developing programmes further.

At the Institute for Extension Studies, University of Tampere, Finland, information professionals are trained to use networked information resources via short course programmes and a career training programme of six months. Students return assignments via e-mail and are trained in using computer conferencing for collaborative writing. In Australia, the Charles Stumert University uses e-mail to communicate with students and has increased the amount of assignments done electronically. The Edith Cowan University uses computer conferencing for on-line tutorials for external students and have placed course materials for undergraduate and postgraduate courses on the World Wide Web. The use of electronic networking in LIS courses in the USA has developed further, with the University of Missouri, Columbia, using video conferencing within their programmes and having just completed a graduate course and a course delivered to information professionals offered via a two way satellite. Syracuse University uses electronic delivery for courses ranging from Information Services and Resources to the Social Context of Information.

At the time of writing the returns to the second survey were still coming in and as a result it is not possible to draw too many conclusions from a small sample. However, the majority of respondents are keen to exploit electronic distance learning but may be restricted by lack of access to the appropriate networks and hardware. Given the rate at which information is appearing in electronic form, and given the way in which networking itself is making access to this information possible, one might assume that this lack of network access will diminish with time as employers of all kinds and types realize the value of network access to relevant information.

As noted earlier, there are some reservations as to whether CPD via an electronic network will 
minimize opportunities for personal interaction that some respondents feel is necessary to facilitate spontaneity in discussions and lead to a sense of isolation.

The results of both of these surveys will identify the factors that will aid further progress and potential course delivery. The subject content of future CPD required by the information workers will be ascertained and a model for future delivery proposed. We are intending to follow up a small number of respondents to both surveys in order to explore in greater depth some of the issues raised. These findings will form part of the final report which is due to be delivered to the British Library in September of this year. This report will then be made available to the profession.

\section{References}

1. John Martyn, J., Vickers, P. and Feeney, M. (ed), Information 2000, London, Bowker-Saur, 1990, p70.

2. Universities Funding Council Circular 8/92. London, 1992.

3. Dorairaju, G., Hämäläinen, M., Krol, J., Mikhi, J., Pätynen, E., Virtamo, J., Alexander, G., Computer support for resource-based collaborative learning at a distance: OU XT001 and the Finnish experience. Proc. Hypermedia in Vaasa '94. Vaasa Institute of Technology, 1994.

4. MacDougall, J., Lewins, H., Tseng, G., Continuing education and training opportunities in librarianship. (British Library Research Paper 74) London: British Library, 1990.

\section{Benchmarking - BLRD\&D funded research at Loughborough University of Technology}

\section{PENNY GARROD}

Department of Information and Library Studies

Loughborough University

\section{Introduction}

Benchmarking is a term which is being used increasingly in the media. The language and trends of the commercial world often pass into common usage in this way. Professor Tony Bendell, author of Benchmarking for competitive advantage refers to a 'benchmarking boom'(1). The problem with the term 'benchmarking' is that it is concrete, not abstract (unlike 'quality'), so it is easier to perceive in terms of products and industry, but less easy to imagine in the context of a service environment. An article in The Economist coined the memorable title 'First find your bench', which highlights the problem ${ }^{(2)}$. Benchmarking smacks of industrial practice. It connotes production lines, inspection, and above all a tangible product which can easily be improved with practical results.

Consequently, there are many definitions and descriptions of benchmarking, and their appeal depends on whether your preference is for the simple, snappy definition or for the more expansive, explanatory style. Definitions often originate from management consultants and Quality 'gurus', and may meet with a degree of scepticism and scorn.

The Department of Trade and Industry's (DTI) booklet on benchmarking contains a useful 